\title{
Positioning the University in the World of Higher Education Research
}

\author{
Brian Foster \\ Provost, University of Missouri
}

ajor research universities are about two main ends: impact and stature.
Impact is really the end goal. It is about training the best professionals,
researchers and others who change the world by conducting research that leads to new technologies, to a new basic understanding of the world, and to new practices in medicine, business or other areas; and it is about delivering highly effective health care, economic development, and other practical services. Impact is the end game, but stature is a necessary condition; it determines the institution's ability to attract the best faculty, students, and staff, and to get grants and contracts that enable research, services, and other means of achieving the greatest impact.

The idea of "positioning" a research university is critical to the objectives of impact and stature. At the University of Missouri (MU), we have focused on this matter in a very purposeful way, recognizing that for $\mathrm{MU}$ to achieve the level of impact to which it aspires, it has to compete effectively with the best universities in the world. To do so, we at Missouri need to compete with the biggest and best universities on our turf, not on their turf. We have to compete in the areas in which we have unique strengths-competitive assets-that allow us to do things that others, no matter how great their stature, cannot.

This article outlines the goals of the Mizzou Advantage-the University of Missouri's approach to positioning the institution in the world of higher education-and the ways $\mathrm{MU}$ is implementing this large and complex initiative.
I. Creating the Concept of the Mizzou Advantage

\section{The Process}

Nearly four years ago, MU began a process to identify the competitive assets (we called them "strategic advantages" then) that could be the foundation for several long-term initiatives that would position the university in the way outlined above. A task force of very prominent and respected faculty was formed by the provost to frame the process, to identify several potential strategic advantages, and to seed a broader discussion with faculty, deans, alumni, students, staff, and others.

With the Task Force's suggestions of possible strategic advantages in hand (about ten of them), the provost organized a broad set of faculty discussions to validate (or eliminate) items on the list, to better articulate them, and to add new ones. These 
discussions took the form of "faculty forums" to which all MU faculty were invited. The idea was to have meetings of no more than fifty people, so that significant interaction and discussion could occur; as many meetings would be scheduled as needed to accommodate all interested faculty. Similar discussions for staff and students were held. Several hundred faculty and others participated in highly thoughtful and productive discussions that provided input to the next round of meetings of the Task Force.

When re-convened, the Task Force carefully considered the input received in the forums and made significant adjustments in the list of strategic advantages. Then, based on this final, refined list, the Task Force turned to identifying five "strategic initiatives" that would be firmly based on the strategic advantages. The five tentative initiatives were then discussed by many faculty and other constituents in venues similar to the earlier faculty forums. Again, several hundred people participated, and the discussions were even more productive, focusing not only on the definition of the initiatives, but also on implementation and expected outcomes.

Following these extremely useful discussions, the Task Force met again to finalize the list of strategic initiatives and to outline a strategy for implementation. Several important principles emerged from the discussions that have shaped the implementation efforts that have now been underway for more than a year. Among the most important was that the initiatives would be VERY interdisciplinary. This builds on MU's very strong interdisciplinary research culture.

There was broad agreement in the forums that we would not create new "silos" such as new centers or institutes, but rather each initiative would be associated with a network of MU faculty, centers, departments, staff, core facilities, and external collaborators including other universities, national labs, corporate partners, research institutes, consulting firms, foundations, and any other organizations or individuals with whom productive collaborations could be formed. Accordingly, the networks would not be guided by a "traditional" administrator (e.g., dean, director), but rather by a facilitator whose charge is to bring people and organizations together in productive collaborations.

There was also broad agreement that the network for each initiative would be very inclusive: the initiatives were framed specifically to allow this breadth of participation (see the descriptions of the initiative areas below). In fact, $\mathrm{EACH}$ of the five can readily include participants in humanities, physical sciences, engineering, biological sciences, professions (medicine, veterinary medicine, law), business, education, journalism, social sciences, agricultural disciplines, and others.

\section{The Five Initiatives}

One Health, One Medicine. One of MU's most important assets is that our programs in Medicine, Veterinary Medicine, and Animal Science are contiguous, and there is significant collaboration in all directions, including joint appointments. Moreover, located between the three is the Bond Life Science Center, a large and very interdisciplinary research facility that brings together not only the three programs above, 
but also faculty, staff, and students from Biochemistry, Biological Sciences, and other units. The One Health initiative is founded on the already strong collaboration of these three units, but it is much broader. For instance, Kansas City is the world's largest center of corporations in the animal health business; MU has many collaborations in this vital environment. Other health units are closely related, including Nursing, Health Professions (e.g., Health Psychology, PT, OT), and Biomedical Engineering. Many other centers also connect strongly to One Health: e.g., the Dalton Cardiovascular Center, the Thompson Center on Neurodevelopmental Disorders, and the University's Research Reactor [the most powerful research reactor on any campus in the US]. Other resources include a state of the art Brain Imaging Center. But beyond such specifically health-related disciplines, there is strong collaboration with areas such as the Trulaske College of Business, the College of Education, literary studies, Psychology, Anthropology, Policy Studies, and the MPH program.

Food for the Future. The University of Missouri is located in the middle of a large and diverse agribusiness area...in fact, agriculture is the largest industry in the state. And on either side of the state are strong agribusiness partners. St. Louis is home to some of the world's most prominent plant science centers, the Danforth Institute and the Monsanto Company. Kansas City, as noted above, is the world's largest location for the animal health industry. Taken together with MU's Plant Science group, one of the three strongest in the country, and the Veterinary Medicine and Animal Science programs, the University is positioned strongly in areas of research related to food and to training world-class professionals in fields related to food. Although the anchors for the Food for the Future initiative are related to food production, the University's resources are far broader. Nutrition and chronic disease, for instance, are strong programs. As with all major industries, most of the key decisions are based on business considerations - an especially complicated and interesting matter given today's global food industry. The culture of food is of great interest to many in the humanities and social sciences (e.g., concerning the central place of food in rituals and ceremonial events throughout the world, the cultural drivers of eating behaviors, the symbolic importance of food in intercultural relations). Policy, environmental, educational, and media coverage of food are areas of interest to MU programs. In today's environment, food safety is a critical concern as is food security (i.e., access to sufficient food for people of lower socioeconomic status). Like One Health, Food for the Future is a topic of vital interest to virtually every academic college at MU.

Media of the Future. It is widely known that MU's School of Journalism is the oldest and arguably the best Journalism program in the world. Also well known is the fact that the media world-especially paper media-is in a state of transformational change, much of which is driven by new digital media, in which the MU School of Journalism has special strengths. The high stature of the School has been greatly enhanced by the founding of the Reynolds Journalism Institute, a world class think tank focused on the future of media. No other university can match the core, forward-looking media presence of MU, but as with the other initiatives, the media initiative stretches 
far beyond the School of Journalism. For instance, it is well known that the impact of digital media on marketing is at least as great as on newspapers and magazines and, accordingly, interest in marketing, advertising, and related topics is great. The implications of changes in media for the American democracy are enormous. Of course, the engineering interest in creation of digital media technologies is great. Policy issues, public information, cultural communications, public education, and other functions depend heavily on media and are in a state of transformation. The processes of education in schools and universities have been dramatically affected by developments in media - an area of very robust research and educational attention at MU. The archival functions of libraries are in a dramatic state of change, as is the world of scholarly publishing-areas of great interest to MU researchers and to the MU Libraries. Again, as with the other initiatives, Media of the Future is of great interest to virtually every unit on campus and to a broad array of external collaborators including media outlets, press associations, other universities, and federal agencies.

Sustainable Energy. MU's location in the middle of an enormous agribusiness area has stimulated substantial interest in biofuels of all kinds, engaging faculty in units as diverse as plant science, agroforestry, and bioengineering. In addition, the presence of the research reactor has stimulated broad educational and research interest in nuclear energy. Of course, both of these areas stimulate great interest in environmental issues and associated legal and policy implications. Environmental issues related to biofuels interact with food production, as does the allocation of agricultural resources which is based primarily on business decisions. The logistics of energy distribution are of great interest as well as energy storage for wind and solar. If storage can be achieved, wind and/or solar become quickly cost effective. The uses of energy are of great interest in many academic units, as in Architectural Studies, in Engineering (e.g., design of vehicles), and in steam production (e.g., the biomass facilities of the MU physical plant, which is a model of national interest and a center of education and research). Energy use of data centers is of interest to MU researchers. Advanced battery technologies, in collaboration with prominent Missouri corporate partners, is a significant research focus of several faculty. The global nature of the energy industry is of great interest in all of the above matters, since energy costs, distribution, production technologies, and other matters are among the main drivers of the global economy. Although the future of the energy industry and our uses of energy are anything but clear, it is entirely clear that our reliance on fossil fuels is not sustainable even for the intermediate future, and new energy technologies, with all of the policy, diplomatic, business, ethical, and cultural implications, will be key elements of our future.

Understanding and Managing Disruptive and Transformational Technologies. One important aspect of the 
four initiatives discussed so far is that all concern areas that are undergoing fundamental change. Many MU faculty and collaborators have focused on understanding these changes. From one critical perspective, business as we have known it in the four areas is approaching chaos and is not sustainable even in the intermediate term; perhaps even more important, future directions are unclear. The same could be said for policy, ethical, cultural, social, and psychological aspects of all four areas: all are changing in fundamental and unpredictable ways. The one thing that is clear is that changing technologies are at the root of many of the changes, though on the surface, these technological developments are playing out in very different ways. In all cases, the dynamics are global, with key inputs from international economic, political, and diplomatic processes. Thus, understanding and managing these dramatic technological changes requires broad academic input from all of the areas mentioned above. In many disciplines there is established research on the management of technological change (e.g., the business literature on disruptive technologies). But environmental, cultural, and political aspects of these changes are of great interest as well. A key element of the technology initiative is to bring together the diverse perspectives on campus to come to a more general understanding and, thereby, a greater ability to manage the volatile conditions in which we find ourselves.

II. Implementation: What are we Actually Going to Do?

We have begun an aggressive, multiyear roll-out of the Mizzou Advantage (the five initiatives collectively). It is important to stress at the outset that MU already has considerable strength in these five areas. Given the breadth of the areas and the dynamic composition of the collaborative networks, it is difficult to estimate the magnitude of the university's activities, but our "back of the envelope" estimate is that we spend approximately $\$ 200$ million total each year, including faculty and staff salaries, graduate assistant compensation, grants, gifts, general operations, facilities costs, fee-for-service contracts, and more. Our goal is to strengthen these broad areas in ways that enhance MU's impact and stature, as outlined above.

Very broadly, we have identified several million dollars that will be directed toward the enhancement of the initiative areas in ways outlined below, and we have created a support structure to help carry out the operations. It is important to stress that the discussion below focuses on the research dimension of Mizzou Advantage, but that there are integral and equally important components for instruction, economic development, and public service.

Mizzou Advantage Activities

Implementation of the Mizzou Advantage began with a series of lunches and late afternoon meetings with hors d'oeuvres to explore possible network connections among individuals, mostly MU faculty, but also a significant number of external people (e.g., CEO of a biological sciences company, head of the Missouri Press Association, and senior faculty from another nearby university). Each of the events was by invitation, the list of invitees coming from discussions of the provost with deans, center directors, and key senior faculty in the initiative areas. These events were extremely lively and 
productive, in many cases bringing together potential collaborators who literally had never met or even heard of each other.

Very shortly after implementation began, the provost issued an RFP for seed grants and networking grants. The latter awarded up to $\$ 20,000$ for symposia, workshops, conferences, or any other kinds of activity that would help build the networks in the five initiative areas. Seed grants of up to $\$ 50,000$ were awarded to long-term, large scale projects that would move the Mizzou Advantage agenda forward. As with the networking grants, a key objective of the seed grants was to bring collaborators together, though in this case working on formation of a specific project. A total of about $\$ 950,000$ was awarded in this first round of grants; a second round will award up to $\$ 1.5$ million late in the fall. A third round, funded from the Chancellor's Fund for Excellence, will be targeted for seed projects with major external collaborators.

The idea of forming strong networks is central to Mizzou Advantage. As suggested above, much of the network creation consists of making relationships between people, academic units at MU, and external partners such as corporations, other universities, national labs, think tanks, and consulting groups. One important way of forming such relationships is by having events on campus that bring potential partners together for relevant interaction. Targeted conferences, workshops, symposia, and other events are an important part of Mizzou Advantage, and one important support function is provision of professional event coordination and planning assistance (see below). It is important to note that the relationships formed in conferences and the events themselves not only support the research networks, but they greatly enhance the vitality of the campus intellectual life.

The creation of networks is not, however, simply a matter of creating relationships among pairs of potential collaborators. The structure of the network is also of great importance-the robustness, size, and focus are critical network elements. For example, it would be unwise to invest heavily in infrastructure to support a network which centered around one key person, loss of whom would destroy the collaborative group's functionality. Nor would a research network be viable if a key "connector" was an ineffective researcher. A diverse set of people at MU are using state-of-the-art network analysis techniques to model our collaborative networks and the potential relationships that could be brought into the networks (e.g., co-investigators on grants, co-authors, co-members of doctoral committees, and faulty who teach classes jointly). (See appendix for a brief sketch of how such structural elements will be considered in Mizzou Advantage.)

Bringing potential collaborators together at a conference, workshop, or just a networking reception is valuable, but productive collaboration will depend in many cases on each getting a better sense of the other's discipline. To assist with this kind of professional development, Mizzou Advantage has budgeted \$200,000 for "faculty 
development" awards each year for a faculty member to attend a meeting in another discipline or otherwise develop needed expertise. These awards, up to $\$ 2,000$, will go to those who are actively developing relationships and projects in the Mizzou Advantage areas; award of these funds will begin in the fall, 2010.

A central part of building strong collaborative networks will be strategic hiring. Funds have been budgeted to provide $\$ 50,000$ in recurring support to incentivize each of twenty-five strategic faculty hires in the colleges and to increase attractiveness of compensation packages by complementing the units' funds. These faculty hires will be targeted to enhance the strength of the networks; many will be interdisciplinary. The colleges/ departments will provide the underlying salary and the largest part of start-up costs, though a significant budget is available to assist with start-up costs as well. Criteria for such hires will include (a) providing a link between two or more clusters of collaborators with potential to position the university prominently if they could come together, (b) providing a critical kind of expertise to move forward a longer-term effort for which other resources are in place, and/or (c) providing a link between a very strong group on campus, a potential collaborator such as a national lab, and an agency with interest in funding a mega project in the area. This kind of hiring will begin only after we have achieved a better understanding of the current underlying networks on campus and will be done over a period of approximately five years. The first search processes will occur within the next year or so. Finally, the Chancellor's Fund for Excellence will sponsor several endowed professorships in the Mizzou Advantage areas.

Similarly, there is budget for a $\$ 250,000$ match to hire each of four very distinguished faculty-e.g., Pulitzer Prize winners or members of the NAS. As with the other twenty-five hires, the Mizzou Advantage match will help units make very attractive offers-e.g., assume a joint appointment with underlying salary of $\$ 150,000$ from each unit plus the $\$ 250,000$ match, totaling a $\$ 550,000$ compensation package. Again, the point of the hires is to strengthen network structures, to bring strong clusters together, and/or make relations with external funding agencies or collaborators. These hires will be made over a period of several years - perhaps one every two or three years - to spread out start-up and other costs that in the short term are likely to be much more costly than salary.

\section{Infrastructure}

A key step in implementation was the appointment of an Advisory Board to assist with all aspects of the definition and operation of the Mizzou Advantage. This board was appointed by the provost and consists of distinguished faculty from a broad range of academic disciplines (arts, humanities, biological sciences, physical sciences, professions, business, education), and of key support staff (e.g., library, IT, Research Office, and Extension). One of its first tasks was to assist in appointing the facilitators and an education coordinator - the key leaders of support functions for the five individual initiatives and the education programs. This board also did the review functions and recommended funding for an initial round of 
networking and seed grant proposals received in response to the abovementioned RFP which was issued about the time the facilitators were appointed.

As noted above, the infrastructure for the five initiatives is unusual insofar as it is not based on centers, institutes, colleges, or other "normal" organizational units. Nor is there a standard line structure of administrators such as directors, chairs, or deans. This point is important, because a key objective of the implementation is to avoid creating new silos, but rather, to make the walls of existing silos very penetrable. It is also important to stress that $\mathrm{MU}$ is committed to sustaining, supporting, and strengthening the academic disciplines that are generally associated with colleges and departments, because our aspirations for the five initiatives of the Mizzou Advantage are based on the synergies that come from the interactions of different disciplines. The goal is NOT to eliminate or compromise the disciplines, but to bring them together in productive, synergistic ways.

The core of the infrastructure is a "facilitator" for each of the five initiatives plus an "education coordinator" who is working with the five facilitators to create educational certificate programs. The facilitators are all senior faculty with expertise relevant to the content of the initiative activities. Their main job is to form the collaborative networks described above - not only linking faculty across department and college boundaries, but also linking individuals and campus units with diverse external entities. The facilitator positions are part-time, a signal to the MU faculty that the facilitators remain first and foremost researchers and teachers, and that the academic life of a facilitator continues to be very similar to that of a faculty member. The facilitators are housed together in a single office suite with the education coordinator; they all meet together regularly, but most of their time is spent in making contacts with potential collaborators, exploring possible projects, and generally creating the collaborative networks that are the core of the Mizzou Advantage. It should be noted, though, that their frequent interaction helps identify and support the overlap of the five areas.

As noted above, it is important that the facilitators are focused not just on making relations among collaborators, but also on constructing robust network structures that are not vulnerable to loss of a single key individual or twonetworks with multiple relations tying clusters of collaborators (people and other kinds of collaborators) together. An important property of the networks is that they are dynamic in membership and structure, since specific collaborators will be more actively engaged at some times than otherssome even uniquely for a specific project-as different funding and other opportunities present themselves. One important element of the facilitators' activities is working with deans and departments in hiring strategically placed individuals to strengthen the network clusters. Each facilitator has a significant amount of discretionary funding-approaching $\$ 100,000$ per year-to seed events and otherwise 
support their network-building activities.

The work of the facilitators and other staff is supported by the Mizzou Advantage coordinator and administrative assistant, who provide a broad range of services, e.g., scheduling meetings, assisting with correspondence, coordinating facilitator relationships with the chancellor's and provost's staff members, with faculty and other academic administrators, and managing relations among themselves and other support staff for Mizzou Advantage.

Other critical support comes in three important functional areas. First, given the central importance of networking - of relationship buildingit is critical that there be effective (and cost effective) support for event coordination. This involves all that it takes to arrange a good event, including web-site design, registration process, blocking hotel space, catering, booking meeting space, arranging needed IT, and so on. Mizzou Advantage has funded new staff for the MU conference office to provide such support. This means that faculty, staff, and others who are arranging conferences, workshops, symposia, and other events related to Mizzou Advantage will have professional support for arranging the logistics of these events and will have virtually none of the faculty and staff time diverted to event arrangements except the networking activity.

Second, it is critical that the faculty have professional support for writing grant proposals. MU has created a national model for a "grant writer network" which has approximately fifteen grant writers distributed across campus, each working in a discipline or discipline cluster environment and thus aware of the specific "customs" and "rules" and "practices" of agencies funding relevant research. Mizzou Advantage has hired a senior grant writer to work with the faculty networks and the grant writer network to provide maximally effective support in proposal preparation.

Third, we believe that the Mizzou Advantage will open opportunities for fund raising that are new for MU. The five initiative areas are such that they may provide opportunities for major gifts from donors with passion in these areas-donors who want to "change the world" in an area for which they have a strong passion. The Mizzou Advantage fund raiser will be building relations with such potential donors based on the idea that MU has world-class programs in these areas that can make a big impact-can, so to speak, "change the world." From a slightly different perspective, if a person is wealthy and would like to leave a mark in a particular area, he or she would be looking for the university (or collaborative network) best suited to "make a mark," and we will argue that the five initiative areas fit such a profile.

A final support function that began two years ago has now been folded into the Mizzou Advantage. It concerns a broad-based effort to cultivate relationships with the most distinguished scholars, practitioners, writers, artists, and others - members of the National Academies, Pulitzer Prize winners, Nobel Laureates, and others of the greatest stature and impact. This effort aims, on the one hand, to increase 
the vitality of campus intellectual life by having MU faculty, staff, students, and collaborators interact with the most powerful intellects. Inviting such distinguished visitors to be keynote speakers at Mizzou Advantage conferences and other events, for instance, serves this purpose. On the other hand, such people are "at the table," so to speak, for conversations that shape the federal and state agendas, that drive research future of different academic disciplines, and that form the long-term research interests of the corporate world. Relationships with such people help MU get in the conversations about shaping the future of research, forming large contract projects by federal agencies, establishing relationships with National Labs, and joining large collaborations in key research and business projects.

\section{Conclusion}

Clearly the Mizzou Advantage is a work in progress in several ways. We have a broad concept that was carefully developed, with the participation of hundreds of people. We received much thoughtful commentary about implementation and operation of the project, but in the end, the process produced a concept, not a well defined structure-as it should be. So, one dimension of the "work in progress" is definition of the structure-of precisely what it is that we are trying to achieve and, very generally, how we will do it. The concept will continue to adapt as the research environment changes, as our positioning develops, and as content areas continue to evolve, but broadly speaking, the "concept" will have continuity over a fairly long time. A broadly inclusive discussion of these basic issues will continue in a purposeful and structured way.

A second dimension is the operational detail of how we will implement the Mizzou Advantage. This goes far beyond the "concept" to the identification of individuals and organizations in the networks, to creation of the support infrastructure, to identifying funds, to proposing and getting funding, building infrastructure, and actually carrying out successful, impactful projects. The changes in the operational details of Mizzou Advantage will be continuous as new projects are initiated, new collaborators are engaged, new networks are formed, and most importantly, as new ideas are created. These changes will be guided by the continuity of the Mizzou Advantage concept or, perhaps better, changing constantly to achieve the Mizzou Advantage vision... and provide a strategic focus and a foundation for moving forward as the current fiscal challenges recede.

A third dimension of the work in progress is telling the story. Although the core ideas are constant, the form of the story varies with different constituent groups. And the story for research is different from the one for education, for economic development, or for delivery of services. The story will also take different directions as the various projects play out, as new people and organizations join the networks, as major contracts and grants are received, and, most importantly, as results of the Mizzou Advantage activities impact research, economic development, students' careers, quality of health care, 
food security-as the activities of goal of impact, of making the world a Mizzou Advantage begin to achieve our better place.

\section{Appendix}
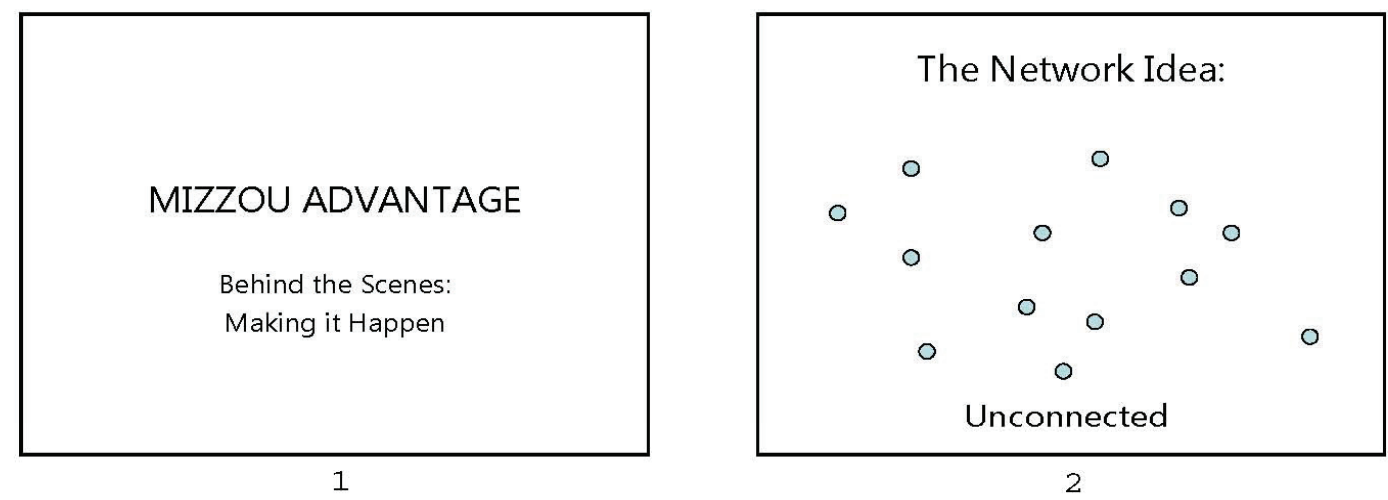

The Network Idea: Not Strong

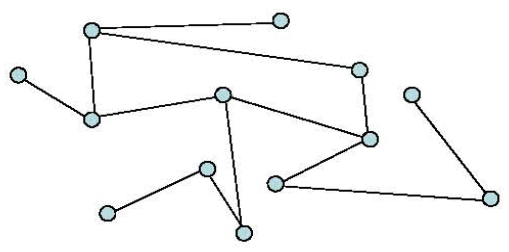

No cluster with all connected to all

3

The Network Idea: Not Strong

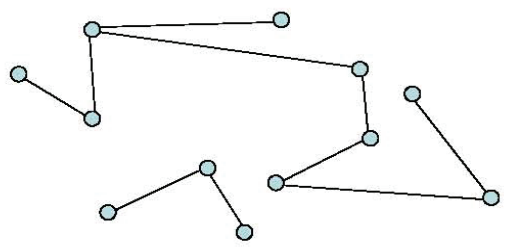

Lose one key node: falls apart

4

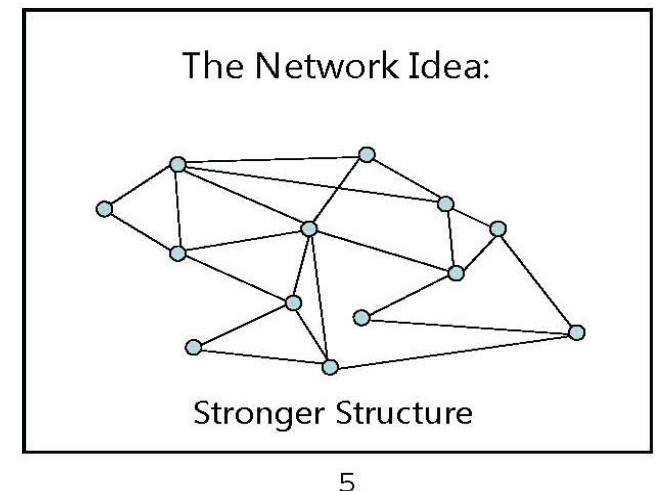

The Network Idea: Strongest?

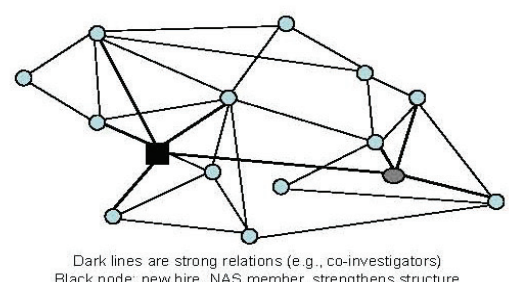

Black node: new hire, NAS member, strengthens structure
Gray node: new hire, strengthens structure, tied to NAS member's cluster

6 


\section{Appendix}

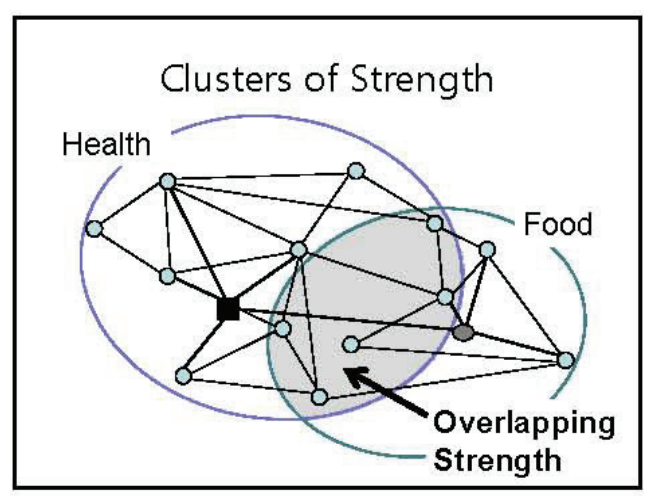

7

Clusters of Strength

becomes

Food/Health

Group

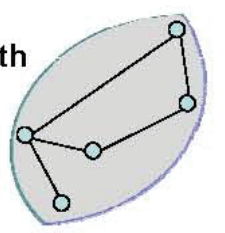

9

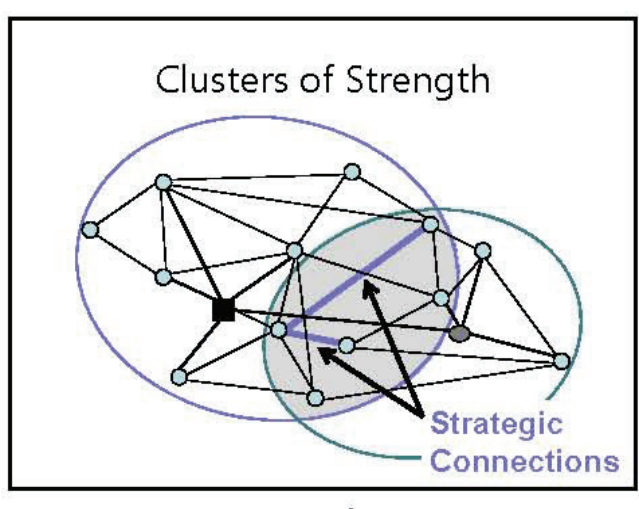

8

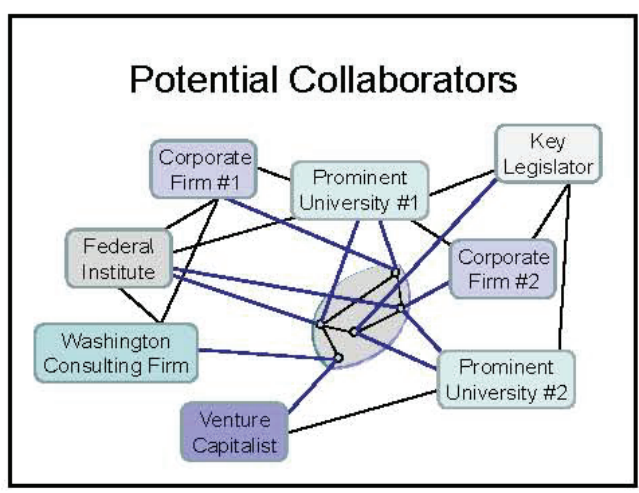

10

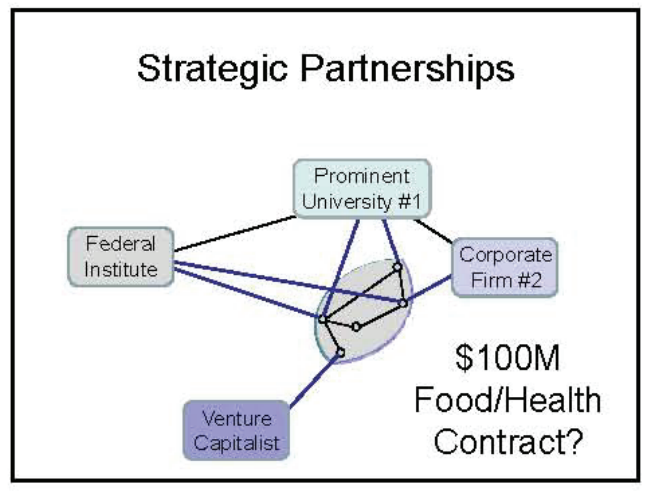

11 